\title{
Obtuse Marginal Artery as the Final Branch of a Long Right Coronary Artery: A Rare Case of a Coronary Artery Anatomic Variant or Anomaly
}

\section{Papagiannis $\mathrm{N}^{\star}$, Stavrianakis D and Moschos $\mathrm{N}$}

Department of Cardiology, General Hospital of Rhodes Island, Greece

*Corresponding author: Papagiannis N, Interventional Cardiologist, Department of Cardiology, General Hospital of Rhodes Island, Greece, Tel: +30 2241 360000; Email: papagianik@yahoo.gr

Received: October 26, 2018; Accepted: November 13, 2018; Published: November 16, 2018

Copyright: (c) 2018 Papagiannis $\mathrm{N}$, et al. This is an open-access article distributed under the terms of the creative commons attribution license, which permits unrestricted use, distribution, and reproduction in any medium, provided the original author and source are credited.

\begin{abstract}
The three primary or 'elementary' coronary arteries and their branches perfuse the heart and originate from the sinuses of Valsalva. Generally, the right coronary artery (RCA) originates from the upper or middle third of the right anterior sinus of Valsalva. It gives rise to the conus branch, one or more acute marginal branches, and if we are talking about right dominant circulation forms the AV nodal artery, the posterior descending artery (PDA) and posterolateral branches. In turn, the left coronary artery originates above the upper or middle third in the left anterior sinus of Valsalva. The left anterior descending artery gives rise to septal branches that curve down into the interventricular septum and diagonal branches that wrap over the anterolateral free wall of the left ventricle. The circumflex artery (LCX) courses clockwise in the AV groove as it gives rise to one or more obtuse marginal branches.
\end{abstract}

Keywords: Coronary anatomy; Circumflex artery; Valsalva; Anginal symptoms; Stenosis; Hypoperfusion

\section{Introduction}

Coronary artery anomalies result from disturbances which may occur to the foetus in the third week of development. These disturbances may lead to anatomical variations which may affect the origin, course, and termination of these arteries, or alterations in their intrinsic anatomy $[1,2]$. Defining the normal and the abnormal in the coronary circulation can be tricky. Paolo Angelini and co-workers proposed that a general definition of normal coronary arteries should be founded on the knowledge of the variations of each of the features used to describe coronary anatomy (number and location of ostia, the diameter or cross sectional area of coronary arteries) [3-10]. Generally each descriptive feature should be considered anatomically normal when it is found in more than $1 \%$ of a general population. On the other hand, morphological features found in less than $1 \%$ of the population should be defined as anomalous coronary anatomy [11-13].

From all the different types of coronary artery anomalies only one sub group is considered to pose risk of causing coronary ischemia: the anomalous origin of a coronary artery from an opposite sinus of Valsalva with an intramural course (ACAOS). It is found in approximately $1 \%$ of adult cardiac catheterization laboratory patients [14-17].

\section{Case Report}

A 45-year-old male patient was referred to our clinic for preoperative coronary angiography, prior to vascular surgery for peripheral arterial disease (severe aorto iliac obstructive disease Leriche syndrome and critical stenosis of the left renal artery). He was smoker, dyslipidemic and had resistant hypertension. He didn't mention any anginal symptoms probably due to severe limitation in his physical activity because of intermittent claudication. The physical examination revealed absent arterial pulses in the lower extremities, normal first and second heart sounds without additional sounds or murmurs, normal respiratory whisper, blood pressure $160 / 110 \mathrm{mmHg}$. The chest X-ray showed normal sized cardiac shadow and pulmonary vasculature. The electrocardiogram revealed sinus rhythm, ST depression with negative T waves in leads II, III, aVF, V4-V6 and ST elevation in aVR. The two-dimensional echocardiogram was within normal limits.

Coronary angiography was performed with access through a $5 \mathrm{~F}$ sheath in the right radial artery. The ostium of the left coronary artery was engaged with a JL3.5, 5F catheter, the left main artery was atheromatous without obstructive disease, the left anterior descending artery had diffuse atheromatosis and $80 \%$ stenosis in the midpart and left circumflex artery was without obstructive coronary artery disease (Figures 1 and 2).

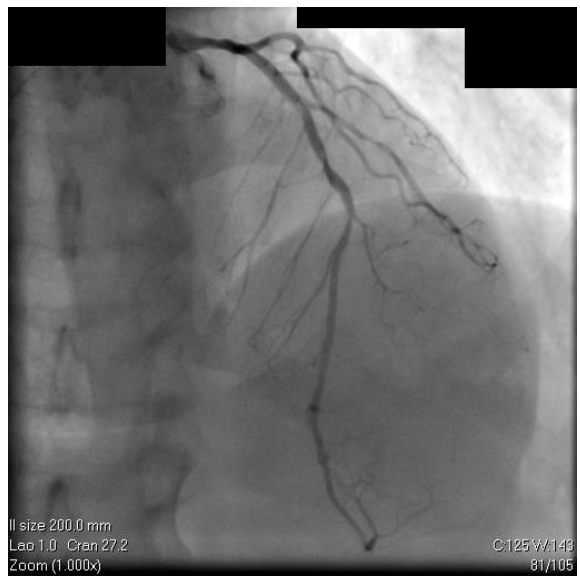

Figure 1: Left anterior oblique view with cranial angulation. 
Citation: Papagiannis N, Stavrianakis D, Moschos N (2018) Obtuse Marginal Artery as the Final Branch of a Long Right Coronary Artery: A Rare Case of a Coronary Artery Anatomic Variant or Anomaly. J Cardiovasc Dis Diagn 6: 344. doi:10.4172/2329-9517.1000344

Page 2 of 3

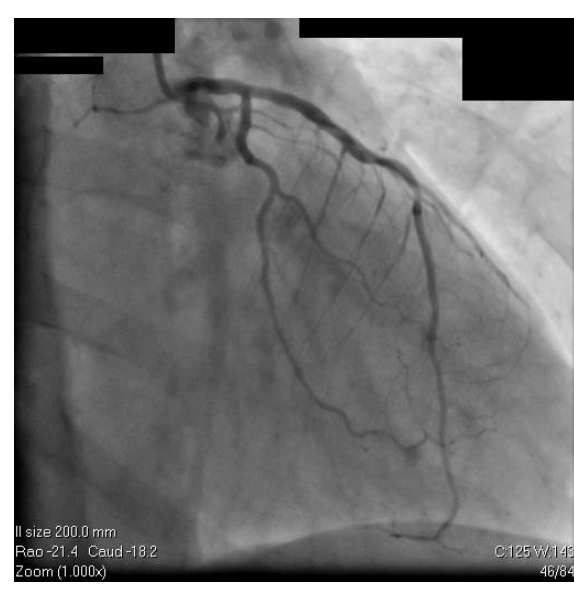

Figure 2: Right anterior oblique view with caudal angulation.

The ostium of the right coronary artery was engaged with a JR4 5F catheter and the artery followed a long course beyond its routine termination, with two successive stenosis $80 \%$ and $90 \%$ respectively, supplying finally the obtuse margin of the lateral free wall of the left ventricle (Figures 3 and 4). All three coronary arteries were with reduced diameters probably due to chronic hypoperfusion.

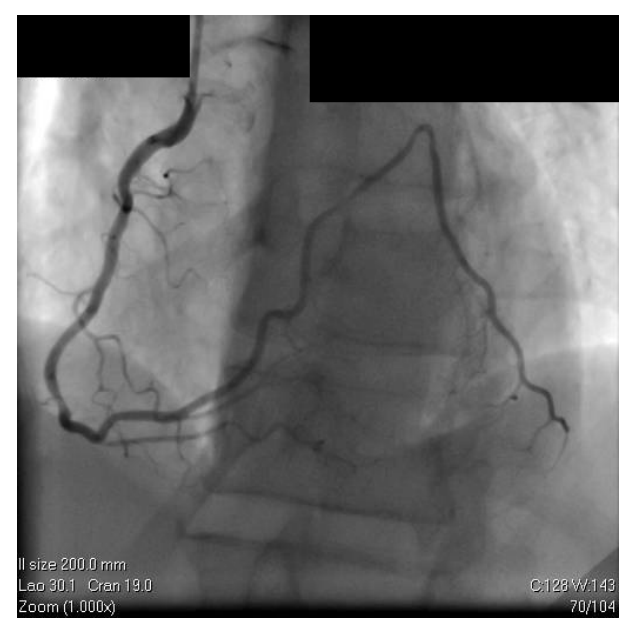

Figure 3: Left anterior oblique view with cranial angulation.

\section{Discussion}

Normally RCA after giving rise to the PDA, continues beyond the crux cordis (the junction of the atrioventricular and interventricular grooves), terminating in one or several posterolateral branches that supply the diaphragmatic surface of the left ventricle. This is the contribution of the dominant RCA to the blood supply of the left ventricle.

In our patient RCA after giving rise to PDA, crosses the crux of heart and ascends across the entire length of the left atrioventricular groove, following an epicardial long course, terminating as an obtuse marginal branch supplying the lateral free wall of the left ventricle.

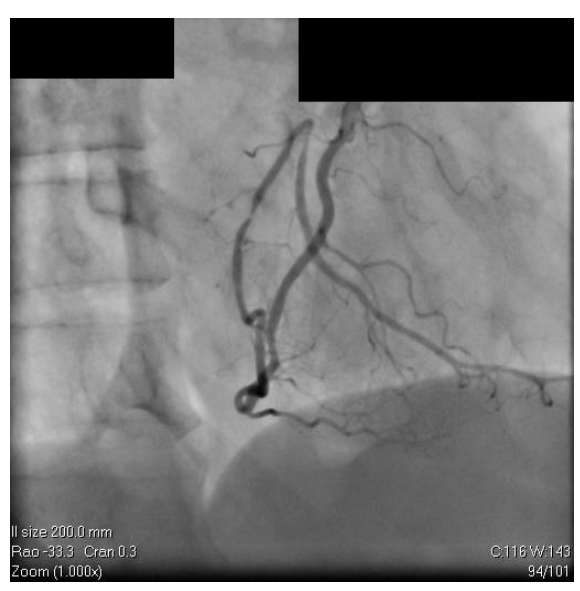

Figure 4: Shallow right anterior oblique view.

Ilia et al. described a case of super dominant RCA with large tortous posterolateral branch for the lateral wall of the heart [18] and Kumar also described anomalous RCA terminating in superior and inferior right circumflex arteries supplying the territory supplied by an absent LCX $[19,20]$. Our patient is a unique case in which the lateral wall of the left ventricle is being supplied by two obtuse marginal branches originating from different coronary arteries LCX and RCA respectively. The clinical consequences of this anatomical variant are determined mainly on the burden of the atherothrombotic disease of the patient and not from the coronary artery variant itself, as it is not known to cause ischemia. Interventional cardiologists and cardiac surgeons should be familiar with these anatomic variants so that a proper revascularization procedure can be obtained in the presence of obstructive coronary artery disease.

\section{Conclusion}

Finally, taking into account the complexity of the disease of our patient, we didn't proceed to any kind of ad hoc revascularization procedure, preferring to clarify first the amount of myocardium in jeopardy with a stress inducible ischemia method and re-evaluate the patient in a multidisciplinary approach.

\section{Conflicts of Interest}

The authors claim that there are no conflicts of interest for the present study.

\section{References}

1. Chiu S, Anderson RH (2012) Can we better understand the known variations in coronary arterial anatomy? Ann Thorac Surg 94: 1751-1760.

2. Young PM, Gerber TC, Williamson EE, Julsrud PR, Herfkens RJ (2011) Cardiac imaging: Part 2, normal, variant, and anomalous configurations of the coronary vasculature. Am J Roentgenol 197: 816-826.

3. Angelini P (1989) Normal and anomalous coronary arteries: Definitions and classification. Am Heart J 117: 418-434.

4. Velden VLB, Bär FW, Meursing BT, Ophuis TO (2008) A rare combination of coronary anomalies. Neth Heart J 16: 387-389.

5. Goldsmith JB, Butler HW (1937) The development of the cardiaccoronary circulatory system. American J Anato 60: 185-201. 
Citation: Papagiannis N, Stavrianakis D, Moschos N (2018) Obtuse Marginal Artery as the Final Branch of a Long Right Coronary Artery: A Rare Case of a Coronary Artery Anatomic Variant or Anomaly. J Cardiovasc Dis Diagn 6: 344. doi:10.4172/2329-9517.1000344

Page 3 of 3

6. Clark EB (1986) Cardiac embryology: Its relevance to congenital heart disease. Am J Dis Child 140: 41-44.

7. Conte G, Pellegrini A (1984) On the development of the coronary arteries in human embryos, stages 14-19. Anat Embryol 169: 209-218.

8. Angelini P (2002) Clinical articles: Coronary artery anomalies-Current clinical issues: Definitions, classification, incidence, clinical relevance, and treatment guidelines. Tex Heart Inst J 29: 271-278.

9. Angelini P, Velasco JA, Flamm S (2002) Coronary anomalies: Incidence, pathophysiology, and clinical relevance. Circulation 105: 2449-2454.

10. Angelini P (2007) Coronary artery anomalies: An entity in search of an identity. Circulation 115: 1296-1305.

11. Raff GL, Abidov A, Achenbach S, Berman DS, Boxt LM, et al. (2009) SCCT guidelines for the interpretation and reporting of coronary computed tomographic angiography. J Cardiovasc Comput Tomogr 3: 122-136.

12. Flessas D, Mamarelis I, Maniatis V, Souretis G, Laschos N, et al. (2013) An unusual pattern of three major components of the cardiovascular system: Multimodality imaging and review of the literature. J Cardiothorac Surg 8: 61.

13. Menke DM, Waller BF, Bless JE (1985) Hypoplastic coronary arteries and high takeoff position of the right coronary ostium: A fatal combination of congenital coronary artery anomalies in an amateur athlete. Chest 88 : 299-301.

14. Yamanaka O, Hobbs RE (1990) Coronary artery anomalies in 126,595 patients undergoing coronary arteriography. Cathet Cardiovasc Diagn 21: 28-40.

15. Yurtdas M, Gülen O (2012) Anomalous origin of the right coronary artery from the left anterior descending artery: Review of the literature. Cardiol J 19: 122-129.

16. Alexander RW, Griffith GC (1956) Anomalies of the coronary arteries and their clinical significance. Circulation 14: 800-805.

17. Angelini P, Walmsley RP, Libreros A, Ott DA (2006) Symptomatic anomalous origination of the left coronary artery from the opposite sinus of valsalva: Clinical presentations, diagnosis, and surgical repair. Tex Heart Inst J 33: 171-179.

18. Ilia R, Jafari J, Weinstein JM, Battler A (1994) Absent left circumflex coronary artery. Catheter Cardiovascular Diagn 32: 349-350.

19. Kumar K (1989) Anomalous course and branches of human coronary arteries. Cells Tissues Organs 136: 315-318.

20. Vijayvergiya R, Jaswal RK (2005) Anomalous left anterior descending, absent circumflex and unusual dominant course of right coronary artery: A case report-R1. Int J Cardiol 102: 147-148. 